now see constantly quoted with approval by the highest medical authorities in Europe and America.

As Editors, we would assert that our opinions are unfettered, and that, while our pages are open to all records and facts worthy of publication, we hold ourselves free to advocate those views which commend themselves to us as most consonant with knowledge, experience, and renson; and we only hope, in the interests of independent medical journalism, that we have heard the last of our relations to Government being an impediment to the honorable course that is open to us.

\section{THERMIC FEVER.}

THE subject of Indian fevers has oecupied so much space in our journal for some months past, that it seems desirable we should, if possible, generalize the opinions of those who have favored us with their observations on this important class of diseases, giving, as it were, an outline of the views held by the majority of the profession at the present time in this part of India regarding the fevers of the country.

The most commonly received ideas as to the causation of fever seem to be capable of classification under two heads-first, that fever is usually induced by influences acting directly on one or more of the nervous centres; and secondly, that fever is caused by chemical action taking place between certain constituents of the body and substances that have been engendered in, or introduced into, the system through, the blood. Without committing ourselves, however, to an expression of opinion regarding the merits of these rival theories, we may, in the first place, consider briefly the circumstances of a form of fever referable to the direct action of heat on the brain.

We need hardly remind our readers that it matters not whether the source of heat is solar or terrestrial. If either men or animals are exposed to an excessive temperature, the heat of their bodies begins slowly to rise, until the stimulus of the heat becomes so intense as to paralyse that portion of the brain which controls the heat-producing power of the body, or it may be the vaso-motor nerves. This effect having been produced, the temperature of the body rises rapidly; intense fever, insensibility, convulsions, and other symptoms of great nervous disturbance set in, succeeded by gradual asphyxia, or a simultaneous failure of circulation and respiration followed by death. In another class of cases death from sunstroke is almost instantaneous. Instances of this description usually occur among persons who have been exerting themselves a good deal, as among soldiers on the line of march; and Dr. H. C. Wood, of Philadelphia, has lately demonstrated the fact that death in cases of this kind occurs in consequence of the myosin of muscles, which have lately undergone great strain, coagulating at a lower temperature than if the muscles have not been overworis. ed. Consequently in the so-called cardiac variety of sunstroke, the patient's blood undergoes but little deterioration, and death is probably due to sudden ante-mortem coagulation of the cardiac myosin, and instantaneous arrest of the heart's action occurring as an immediate consequence of the excessively high temperature to which the patient's body has risen.

In the majority of cases of coup-de-soleil met with in this country, the thermic fever is preceded by marked prodromes and symptoms referable as above described to the paralysing effects of heat on certain parts of the cerebrum, or vaso-motor nerves. It is quite true, as Indian observers have long since remarked, that in sunstroke the blood becomes dark; it loses its power of coagulability, resembling the blood seen in low fevers generally, but if injected into the veins of a second animal, it produces no ill-effects; and Dr. Wood lays great stress on the fact that this abnormal state of the circulating fluid is preceded by the nervous symptoms; in fact, that the dark, thin, grumous blood is due to the rapid tissue changes induced by the fever and a more or less complete arrest of excretion. The amount of oxygen in the blood is at the same time lessened, as the result of partial asphyxia, combined with the abnormal consumption of oxygen by the tissues; but the amœboid movements of the white corpuscles are not destroyed, and the dark blood, if exposed to the air, quickiy regains its normal scarlet colour; and further, if the temperature of the patient's body be reduced before permanent injury has been done to his nervous system, by the excessive heat to which he has been exposed, the fever subsides, and he speedily recovers his senses. Dr. Wood's experiments on animals seem to have demonstrated to a certainty the connection between excessive heat applied to the cerebrum, and the characteristic symptoms of sunstroke, the high temperature to which the head of the animal was exposed directly inducing the phenomena of thermic fever, and the withdrawal of the exciting cause of the abnormal action, means at the samertime being taken to reduce the temperature of the body, being followed by restoration to health. Evidently, therefore, in cases of this description, the high fever which tends rapidly to destroy the patient is produced by an influence (heat) acting directly on the cerebro-spinal axis. Dr. J. Lerick, as far back as 1859, was impressed with this view of the matter. He writes:- "I cannot, however, divest my mind of the belief that in sunstroke the unnatural condition of the blood is a secondary affection, not the primary one; that there is in the first place an exhaustion or depression of the nerve force which regulate nutrition, respiration, circulation, and the other acts of organic life." We may, however, remark that although in coup-de-soleil the pupils are contracted, indicating a suspension of power or paralysis of the vaso-motor system, we do not discover after death, as a rule, any considerable amcunt of congestion of the brain, or serous or hæmic effusions into its ventricles or substance; but we do find decided indications of paralysis of respiration. The right side of the heart and pulmonary arteries are gorged with dark fluid blood, and in fact, we discover venous congestion throughout the body; the blood appears to leave the arterial system, and collect in the venous trunks, the arterial coats being often stained red, apparently from the altered hæmatine of the blood. But all these pathological changes are subordinate conditions referable to the fact, as Dr. Wood remarks, "that heating the brain substance of a mammal produces sudden insensibility with or without convulsions at a temperature of $108^{\circ} \mathrm{F}$, and death when the temperature of $113^{\circ}$ is reached; that this effect of the local application of heat is not due to congestion, but to the result of the direct action of the heat on the cerebrum, and that consequently the nerve centres are as perniciously affected by high temperature as the muscles are"-in this way inducing the train of symptoms which constitute thermic fever, or in other words sunstroke. Some two years ago we urged our readers to let us have details of any cases of sunstroke that came under their notice, with accurate observations of the temperature of the patient's body during the course of the attack. Information of the kind is very 
much required, and those who furnish it will add considerably to the advance of the clinical history of this form of disease.

\section{THE CALCUTTA MEDICAL COLLEGE.}

The Calcutta Medical College has now completed the thirtyeighth year of its existence. The annual ceremony of distributing prizes at the close of the session took place on the $3 \mathrm{rd}$ of May. Dr. George Smith presided. We re-produce his eloquent and suggestive address on another page. The distribution took place in the new University Hall, which is admirably adapted for such purposes in every respect, save the important one of accoustics. We trust that measures may be adopted to remedy this defect, which was no less apparent at the recent convocation of the University than at this meeting. There was a goodly attendance of the Professors and Teachers of the College, of those interested in the institution, and of the friends and relations of graduates and pupils. Dr. D. B. Smith, the Officiating Principal, opened the proceedings by reading the report of the session. He enumerated the changes which have taken place among the professors, and dwelt in suitable terms on the very sad loss which the College has sustained in the death of Surgeon J. A. P. Colles, to whose estimable character and unselfish derotion to his work he paid a high tribute. The bestowal of the well-earned distinction of Rai Bahadoor on Baboo Kannaye Lall Dey, the accomplished native teacher of chemistry, was also acknowledged as a graceful honor conferred by the State on himself, his College, and the serrice to which he belongs. The statistics with which Dr. Smith illustrated his report, indicate the marrellous progress of this great school of medicine. The strength of the various classes during the last 13 years is shown in the following table, which speaks for itself :-

\begin{tabular}{|c|c|c|c|c|}
\hline $\mathrm{Y}_{\mathrm{EARS}}$ & $\begin{array}{l}\text { Primary } \\
\text { Class. }\end{array}$ & $\begin{array}{l}\text { Bengali } \\
\text { Class. }\end{array}$ & $\begin{array}{c}\text { Military } \\
\text { Class. }\end{array}$ & Total. \\
\hline 1860 & 160 & 144 & 131 & 435 \\
\hline 1861 & 180 & 134 & 95 & 409 \\
\hline 1862 & 200 & 146 & 64 & 410 \\
\hline 1863 & 186 & 156 & 70 & 412 \\
\hline 1864 & 189 & 193 & 91 & 473 \\
\hline 1865 & 177 & 226 & 123 & 526 \\
\hline 1866 & 196 & 242 & 156 & 594 \\
\hline 1867 & 233 & 304 & 188 & 725 \\
\hline 1868 & 243 & 327 & 163 & 753 \\
\hline 1869 & 273 & 353 & 104 & 730 \\
\hline 1870 & 341 & 443 & 135 & 919 \\
\hline 1871 & 388 & 508 & 150 & 1,046 \\
\hline 1872 & 445 & 635 & 146 & 1,226 \\
\hline
\end{tabular}

One hundred and six students passed the final examination at the close of the session : of these, 69 were declared qualified to act as independent medical practitioners, and 37 as hospital assistants. More particularly, 25 belonged to the primary or Englisb class, which furnishes Sub-Assistant Surgeons to the public service, and highly qualified medical practitioners to the people; 6 to the hospital apprentice class, which stocks the subordinate department of the Indian Medical Service for duty with British troops, and some of whose members also fill important civil charges; 29 to the military or "native medical pupil" class, which supplies hospital assistants for subordinate service in sepoy regiments and rarious civil charges; and 46 to the Bengali classes, most of whose members render invaluable service in the dispensaries, jail, or police hospitals of Bengal, some of them settling among the people in country towns and villages as medical practitioners. Nothing can indicate the great progress and success of the Calcutta Medical College, and its appreciation by the educated classes of Bengal, better than the remarkable increase in the number of payingstudents. The amount of schooling fees realized has risen steadily from Rs. 1,410 in 1860 to Rs. 30,568 in 1872 . The number of students who paid for their own education amounted last session to 759,62 per cent. of the whole ; the remainder holding scholarships, stipends, or free presentations. The M useum of the College was enriched during the session by an addition of 228 morbid specimens, and 893 subjects were dissected.

These figures are extremely satisfactory, and amply justify the warm colours in which Dr. George Smith depicted the progress, services, and prospects of the school. Dr. Smith gracefully alluded in his address to the conspicuous benefits which the Indian Medical Service has rendered to the State and to India, both in war and in peace; and the Calcutta Medisal College, which has attained its present place of importance and usefulness entirely through the efforts of officers belonging to this service, is perhaps the greatest of its peace triumphs. However satisfactory the success already achieved may be, there is still much to be done ere the Medical College can be pronounced equal to its rapidly growing responsibilities. Two defects stand out prominently, which call for immediate remedy. One is a very radical and embarrassing want-namely, the want of a proper building. It has become painfully evident that the classes have outgrown their accommodation. The lecture-rooms are overcrowded, and the reception of oral instruction must be all but impossible where there is hardly standing room for the students. This, we believe, is the case with the vernacular classes. The dissecting-rooms are a series of sheds, and the practical chemistry-rooms of cellars. It is the bounden duty of the State to provide this great and growing institution with proper accommodation and due facilities for conducting practical instruction, without which a medical education is imperfect, if not actually mischievous. The matter will not admit of longer delay, and the sooner a provision, which is ultimately inevitable, is promptly and handsomely made the better. The other defect-and it is also a vital one-is the want of books. Owing to an order which was issued in 1871, prohibiting the local purchase of books, and directing that all additions to the library should in future be made by indent on the Secretary of State, difficulty and delay have arisen in adding to this so necessary element in the teaching appliances of a medical school. Only 19 additions were made to the College Library during the year, and the most of these were presentations. Nothing can be more unfortunate and lamentable than a system which admits of the library of a school becoming antiquated and imporerished. Dr. George Smith made a strong appeal to the wealthy natives of Calcutta and Bengal, urging them to endow the College Library so as to enable it to obtain the newest editions of standard books, and the earliest issues of new books immediately on their publication (and this is what is wanted), and we most cordially endorse his appeal, and trust that very soon it may meet with a liberal response. Medical science is making very rapid strides in these days, and the mass of meciical literature, which is ever issuing from the press, is surprising. Without an 